\title{
The Determinants of Bilateral FDI: Is Asia Different?
}

\author{
Peter A. Petri \\ Brandeis University and East-West Center
}

March 24, 2010

\begin{abstract}
Intra-Asian foreign direct investment (FDI) is dominated by flows from high technology economies to medium technology economies, while FDI elsewhere primarily consists of flows among high technology economies. This distinctive pattern is not due simply to differences in the relative distribution of Asian FDI recipients by technology, or to systematic differences in Asia's technology characteristics. A gravity model analysis is used to explore whether Asian FDI patterns differ significantly from those elsewhere, and if so, in what ways. The results show that Asian FDI flows, in contrast to other FDI flows, systematically favor hosts with relatively low technology achievement and relatively strong intellectual property rights regimes. This type of "Asian exceptionalism" is consistent with "flying geese" theories that have argued that Asian development is the result of technology flows among economies that occupy nearby rungs of the technology ladder.

JEL Classifications: F21, O33, O34.
\end{abstract}

Key phrases: foreign direct investment, FDI, Asia, technology transfer, gravity model, intellectual property rights, flying geese paradigm.

An earlier version of the paper was presented at the International Conference on Investment Technology Spillovers and East Asian FTA Proceeding, in Shanghai on October 10-11, 2008. The conference was organized by Fudan and Brandeis Universities and sponsored by the Japan Foundation. 


\section{The Determinants of Bilateral FDI Flows: Is Asia Different? Peter A. Petri ${ }^{1}$ Brandeis University and East-West Center}

Technological upgrading has played a central role in East Asian development, second only to the region's export orientation. Most of East Asia's miracle economies started low on the global technology ladder but moved up fast to become producers and exporters of technologically sophisticated products. They acquired technology by many means, ranging from legal and sometimes illegal imitation of foreign technology to formal channels such as licensing and direct investment. The region's early stars (Japan, Korea, Taiwan) typically relied on reverse engineering and occasional licensing, while late developers (Southeast Asia, China, and most recently India, especially in its service sectors) emphasized technology imports through foreign investment. Late developers increasingly imported technology from the early stars, which have become significant sources of know-how and investment.

This paper finds that Asian FDI flows differ significantly from those in other regions in ways that make them especially conducive to technology transfers. Asian FDI is dominated by flows from relatively high technology economies to relatively low technology economies, while the rest of the world's FDI connects mostly similar, high technology economies. This "Asian exceptionalism" turns out to reflect not only differences in the relative emphasis on vertical and horizontal FDI, but also differences in the determinants of FDI. Technology-related aspects of the environment have different and greater effects on FDI in Asia than elsewhere. Specifically, large technological gaps and strong property rights help to drive investment in Asia, but are much less significant for investment elsewhere.

The results of the paper provide support for the well-known "flying geese" model of technological development (Akamatsu 1962, Kojima 2000) which argues that Asia's

\footnotetext{
${ }^{1}$ The author is grateful to Mr. Yuki Masujima, a doctoral student at Brandeis University, for excellent research assistance.
} 
technological progress depends on interregional transfers of technology and related industrial development from more advanced economies to less advanced ones. They are also consistent with the finding that in some Asian economies significant spillovers are associated with FDI (for example in this issue by Du et al. 2010, and Xu and Sheng 2010). In Asia, at least, both economy-wide and microeconomic evidence suggest that foreign direct investment leads to the diffusion of technological progress and is instrumental in connecting advanced economies to those following them.

This study uses bilateral FDI flows collected on a one-time basis by UNCTAD from balance of payments data. ${ }^{2}$ Aside from this dataset, bilateral FDI analysis is usually based on OECD data for major source countries. Those data are not complete enough to support global FDI analysis as attempted in this paper; for example, the OECD dataset does not include most intra-Asian FDI flows, which we here find to be distinctive. To be sure, the balance of payments data, which are based on financial transactions, provide noisy and imperfect measures of direct investment flows. For this reason, the IMF has recently commissioned a survey to develop international data on bilateral FDI. In the meantime, UNCTAD's global dataset, despite challenges associated with its balance of payments definition, allows insights into differences in regional FDI patterns that are not possible with more limited datasets.

\section{FDI and technology transfer}

Most contemporary theoretical treatments of FDI are built on the "ownershiplocalization-internalization" (OLI) paradigm of Dunning (1977) as refined in the "knowledge-capital" models of Markusen (1995) and Carr et al. (2001). In this theory, FDI requires three conditions to be satisfied. First, the source firm has to own some production-related asset-brands, technology, or management skills - that is a public good to activities inside the firm and to those licensed by it. Second, production facilities in the host country have to benefit from localization advantages, such as tariff preferences

\footnotetext{
2 The database can be accessed through the UNCTAD FDI portal: http://www.unctad.org/Templates/Page.asp?intItemID=1923\&lang=1
} 
(leading to the production of goods similar to those produced at home, or horizontal investment as in Brainard 1993, 1997) or low-cost inputs (leading to production that exploits advantages and differs from production at home, or vertical investment, as for example in Markusen and Maskus 1999). Third, the source firm has to find it advantageous to combine its assets with host production benefits internally through direct investment, rather than externally through licensing or contracts. Since most firms find it expensive to operate abroad, the decision to locate abroad must reflect a market failure that makes it necessary to link ownership and localization through internalization.

Since technology is often the critical source-firm asset, technology flows play an important role in empirical tests of the OLI paradigm. Technology flows occur with both horizontal and vertical FDI, but vertical FDI has a greater potential for transferring technology because it results in production facilities that are tailored to the production environment of the host economy. This paper attempts to unravel the factors that cause FDI to flow from advanced source countries to less-advanced host countries, that is, in ways that support technology transfer. Such flows are not dominant in most global FDI flows, but are dominant in East Asia. Since the goal is to identify the determinants of intra-Asian FDI flows, the paper is best seen as a contribution to the narrower literature on the technology-related determinants of FDI, as surveyed for example by Saggi (2002).

The OLI paradigm points to two dimensions of technology as potential determinants of FDI. First, the technological gap between potential source and host countries is likely to affect the scope for FDI based on the ownership of technology assets. Second, the institutional framework for technology transfers - especially the strength of the intellectual property rights (IPR) regime in the host country-is likely to affect the willingness of firms to use FDI as the channel to link assets to host production benefits.

Building on work by Krugman (1979) on the imitation of Northern technology in the South, Helpman (1993) and others have examined how IPR regimes can affect investment and trade in theoretical models by varying the rate of imitation of Northern technology in the South. This work generally concludes that the FDI-IPR regime link is 
ambiguous. On one hand, a strong IPR regime slows imitation and makes firms from technologically advanced countries more willing to invest in countries where technology is vulnerable to leakage. This point is confirmed by survey results (Mansfield 1994, 1995) that show that multinationals are especially concerned with the quality of the host's IPR regime in industries where knowledge inputs are large. But on the other hand, strong IPRs make it safer to transfer technology via arms-length transactions such as licensing, so the net effect on FDI flows cannot be predicted.

A significant empirical literature has developed on estimating the determinants of FDI by US and other developed country firms. Until recently, the results have been mainly negative. Ferrantino (1993) found little explanatory power for a variable that measured host country membership in international IPR conventions. Maskus and Konan (1994) also found no significant effects using a different IPR measure. Of course, these studies cannot determine the reason for the absence of an empirical relationship. It is possible that technological leakage is not significant in discouraging FDI, or even if it is, IPR policy can do little about it. It is also possible that the offsetting implications of technology policy for FDI — some positive, some negative - are hidden in aggregations of firms pursuing different strategies.

More recent studies, however, have begun to uncover more subtle relationships. Smith (2001) used patent protection as an explanatory factor and found only slightly significant positive effects for such protection on US affiliate sales and licensing, but interestingly found that the effect became clearly significant when the IPR variable was interacted with the host's capacity to absorb technology. In a firm-level study of Eastern European FDI, Javorcik (2004) found no overall effect from an IPR index, but did find a significant positive effect when the index was interacted with a dummy variable for technologyintensive sectors. She also found that a weak IPR regime generated more FDI, but in activities related to distribution rather than production. Evidently, in models that introduce controls for a firm's investment strategy, it becomes possible to identify a link between FDI and technology policy. 


\section{The hypothesis of Asian exceptionalism}

While the mainstream FDI literature is now turning to differences in firm investment strategies to explain investment flows, a separate literature has long argued that East Asia investment strategies are distinct from other regions in part because of technology transfers. The hypothesis argues that because Asian resource endowments are similar, countries differ in development primarily due to technology. As countries move up the technology ladder, they become more competitive in technologically advanced products and exports. This opens opportunities for followers. Firms in leading countries drive this pattern by transferring technologies to next-stage producers, typically through FDI. Their motivation is of course not to foster the transfer process, but to use their technological assets as long as possible after their domestic production advantage wears off. As a result, Asian FDI is more often driven by the conditions for technology transfer than by economies of scale or factor price differences, as is the case with Western flows.

As already noted, these arguments first appeared in the "flying geese" hypothesis. Applications have shown, for example, that Korean export patterns followed Japanese patterns more closely than might have been expected on the basis of factor endowments, and that this pattern was facilitated by a broad effort to import Japanese technology (Petri 1988). Since Korea's strategy eschewed inward FDI, it relied heavily on technology transfers through reverse engineering and hiring Japanese technical consultants. Interestingly, such patterns are now also beginning to emerge in Eastern Europe (Damjian and Rojek, 2007).

The flying geese paradigm has varied implications, but suggests, among other things, that intra-Asian FDI will be more strongly driven by technology determinants than investment elsewhere. We test this hypothesis by examining the role of variables associated with the technology-transfer motivation, namely variables representing the source country and host country technological assets and the policies that affect the leakage of technology.

The technology hypotheses are examined in the framework of a gravity model of foreign direct investment flows. In the case of international trade flows, reasonable general 
equilibrium theoretical foundations have been developed for the gravity approach (Anderson and van Wincoop 2003). This is not yet the case for FDI, but the model has proved successful in empirical applications (Bloningen 2005). Its basic formulation is:

$$
F D I_{s h}=a+X^{D}{ }_{s h} \beta^{D}+X_{s}^{S} \beta^{S}+X^{H}{ }_{h} \beta^{H}+u_{s h}
$$

where $F D I_{s h}=$ foreign direct investment by course country $s$ in host country $h$ $X^{D}=$ transaction cost indicators between $s$ and $h$ $X^{S}=$ source country characteristics $X^{H}=$ host country characteristics $\beta=$ coefficients $u=$ IUD error term

We will extend this model by including variables that affect technology transfers. Two types of variables will be identified: those that affect the science and technology capacities of source and host countries, and those that affect the policy environment for technology transfer. Adding these variables the model becomes:

$$
\begin{aligned}
& F D I_{s h}=a+X^{D}{ }_{s h} \beta^{D}+X^{S}{ }_{s} \beta^{S}+X^{H}{ }_{h} \beta^{H} \\
& +X^{A S}{ }_{s} \beta^{A S}+X^{A H}{ }_{h} \beta^{A H}+X^{P S}{ }_{s} \beta^{P S}+X^{P H}{ }_{h} \beta^{P H}+u_{s h}
\end{aligned}
$$

where $X^{A S, A H}=$ technology achievement indicators in source and host countries $X^{P S, P H}=$ technology policy indicators in source and host countries

Finally, the model is used to test whether the technology-related determinants of FDI differ across regions, and more precisely, whether the investment strategies of firms in Asia are more influenced by technology-based drivers than elsewhere. This requires adding interactions of technology variables with a dummy variable set to one if both source and host are Asian:

$$
\begin{aligned}
& F D I_{s h}=a+X^{D}{ }_{s h} \beta^{D}+X^{S} \beta^{S}+X^{H}{ }_{h} \beta^{H} \\
& +X^{A S}{ }_{s} \beta^{A S}+X^{A H}{ }_{h} \beta^{A H}+X^{P S}{ }_{s} \beta^{P S}+X^{P H}{ }_{h} \beta^{P H} \\
& +D_{s h} X^{A S}{ }_{s} \delta^{A S}+D_{s h} X^{A H}{ }_{h} \delta^{A H}+D_{s h} X^{P S}{ }_{s} \delta^{P S}+D_{s h} X^{P H}{ }_{h} \delta^{P H}+u_{s h}
\end{aligned}
$$

where $D_{s h}=1$ if $s$ and $h$ in Asia, 0 otherwise 


$$
\delta=\text { coefficients of Asian exceptionalism }
$$

Based on estimates of this model, we will examine the following hypotheses relating to the effects of technology on FDI generally, and more specifically on divergences between coefficients for Asia and those of the global sample:

H1: Source countries with high science and technology achievement invest more abroad than those with lower scores.

H2: Source countries invest in host countries with substantially lower science and technology achievement.

$\mathrm{H} 3$ : Host countries with strong technology policy regimes attract more foreign investment.

H4: Intra-Asian FDI flows are more significantly affected by technology determinants than flows in other regions.

\section{Empirical patterns of global and Asian FDI}

To UNCTAD dataset relies on a relatively consistent definition of FDI, based on the international financial transactions undertaken by multinational firms. ${ }^{3}$ It was collected on a one-time basis for 1998 through 2003 for some 98 countries with 140 partners. Not all countries had data for all years. To make a more consistent analysis possible, the dataset was pared down in this study to bilateral transactions among 85 countries with relatively good coverage. The year 1998 was omitted due to the disruptive effects of the 1997-98 financial crisis. The empirical analysis is based on aggregate five-year flows were used for the remaining years, rather than the underlying time-series panel, to compensate for high annual variability. The partner distribution of the FDI inflows observed during this period was inflated with actual FDI inflow totals for the 2002-06

\footnotetext{
${ }^{3}$ For a comprehensive survey of empirical studies see Blonigen (2005) Most work is based on FDI statistics that rely on the definitions of boards of investment and other national gateways to the investment process that tend to be more variable across countries.
} 
period. Thus, the estimates reflect recent, consistent 5-year FDI totals with partner compositions based on the somewhat earlier (partially overlapping) dataset.

Global FDI flows over 2002-06 were approximately $\$ 3$ trillion, of $1.3 \%$ of GDP on an annual basis, and rose gently within this period (Table 1). Outflows accounted for a larger percentage of income in developed economies (1.8\%) than in developing ones $(0.3 \%)$, but rates of inflows were roughly similar. Asian economies were roughly in line with global averages, except for Japan, which has unusually low inflows and outflows. Because Japan is Asia's largest economy, the region's inflows and outflows relative to income are somewhat below global averages. Overall, Asia received nearly $25 \%$ of world FDI inflows and was responsible for $13 \%$ of world outflows. Half of outflows were by newly industrialized economies (Hong Kong, Korea, Singapore and Taiwan) accounting for more than twice as high a share of their GDP as was the case for developed countries in general.

TABLE 1. GLOBAL FDI

\begin{tabular}{lrrrrr}
\hline & \multicolumn{1}{c}{ GDP } & \multicolumn{2}{c}{ FDI Flows, 2002-06 } & \multicolumn{2}{c}{ Annual FDI/GDP } \\
& PPP 2007 & Inflows & Outflows & Inflows & Outflows \\
\hline Asia & 10,657 & 701 & 400 & $1.3 \%$ & $0.8 \%$ \\
China & 2,871 & 309 & 33 & $2.2 \%$ & $0.2 \%$ \\
Japan & 4,599 & 20 & 134 & $0.1 \%$ & $0.6 \%$ \\
India & 933 & 39 & 2 & $0.8 \%$ & $0.0 \%$ \\
NIEs & 1,276 & 241 & 221 & $3.8 \%$ & $3.5 \%$ \\
ASEAN5 & 895 & 81 & 10 & $1.8 \%$ & $0.2 \%$ \\
CLMV & 84 & 11 & 0 & $2.7 \%$ & $0.1 \%$ \\
Other developed & 29,065 & 2,284 & 2,598 & $1.6 \%$ & $1.8 \%$ \\
Other developing & 7,309 & 657 & 124 & $1.8 \%$ & $0.3 \%$ \\
World & 47,031 & 2,985 & 2,998 & $1.3 \%$ & $1.3 \%$ \\
\hline Billions of & \multicolumn{5}{c}{}
\end{tabular}

FDI data were matched with several other types of information for purposes of analysis outlined in Equations (1-3):

- Determinants of FDI outflows and inflows $\left(\mathrm{X}^{\mathrm{S}}, \mathrm{X}^{\mathrm{H}}\right)$ such as market size and per capita income. 
- Determinants of FDI flows between countries $\left(\mathrm{X}^{\mathrm{D}}\right)$ such as distance, contiguity, sharing a common language, and links through airports and waterways. These were made available by Christopher Magee (Magee 2003).

- Determinants of the technology environment $\left(\mathrm{X}^{\mathrm{A}}, \mathrm{X}^{\mathrm{P}}\right)$, including indexes of science and technology achievement and science and technology policy.

The construction of the variables is described in Annex A. The technology indexes were based on the UN Human Development Report 2008, the International Finance Corporation's Doing Business, and recent IPR rankings (Horst 2007). Using these sources, the technology achievement index was constructed as a composite rank of an economy's indicators of telephone subscriptions, internet users, patents, royalty and license fees, research and development expenditures and the number of researchers. The technology policy index was constructed as a composite rank of an economy's indicators for its legal and political environment, physical property rights, intellectual property rights, registration of property, protection of investors, and contract enforcement.

A useful place to begin analyzing this information is by reviewing the world pattern of FDI flows classified by the technology characteristics of investor (source) and host countries. Figure 1 reports the shares (or total world FDI) in the different pair-wise relationships among investors and hosts, and shows that approximately $70 \%$ of world FDI involves both source and host economies with the highest values of the technology achievement index. Flows from high-tech economies to medium-tech economies are substantially lower (and as we shall see below, much of these flows are in fact intraAsian). Beyond these two relatively high bars, the world FDI landscape is barren: few medium- or low-tech economies engage in FDI, and even fewer medium- and low-tech hosts receive FDI from them. 


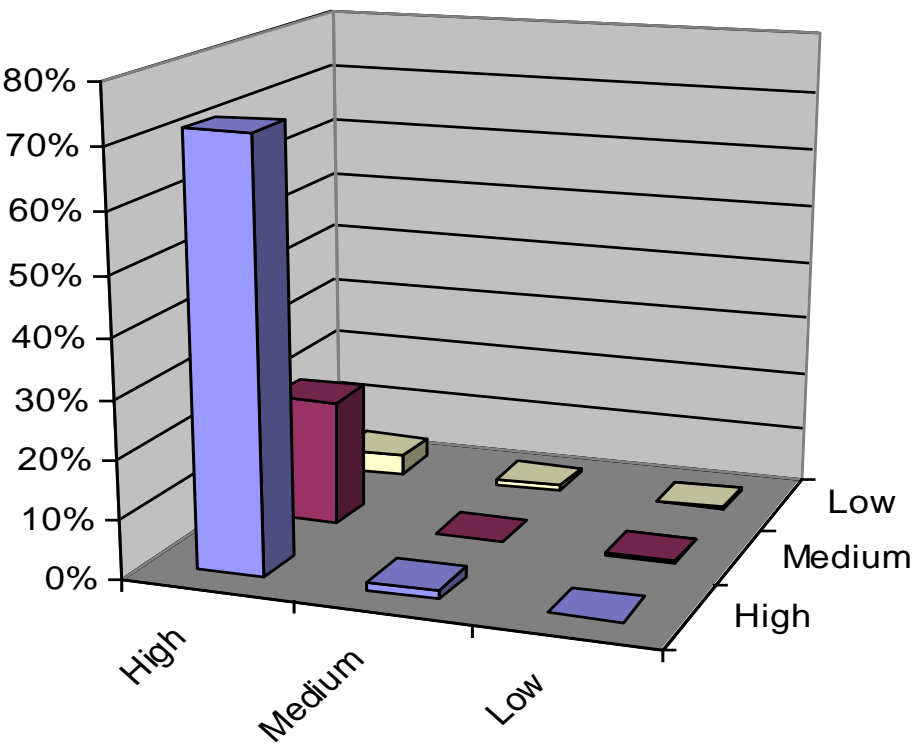
of Host

\section{Technology Achievement of Investor}

These patterns are very different in Asia, as shown in Figure 2. This figure is dominated by flows among economies at different levels of technological development, and specifically by flows from high- to medium-technology economies. More than $60 \%$ of this FDI involves flows from high-tech to medium-tech economies, involving both Japan and the NIEs as sources, and a wide range of lower-income economies as hosts. 


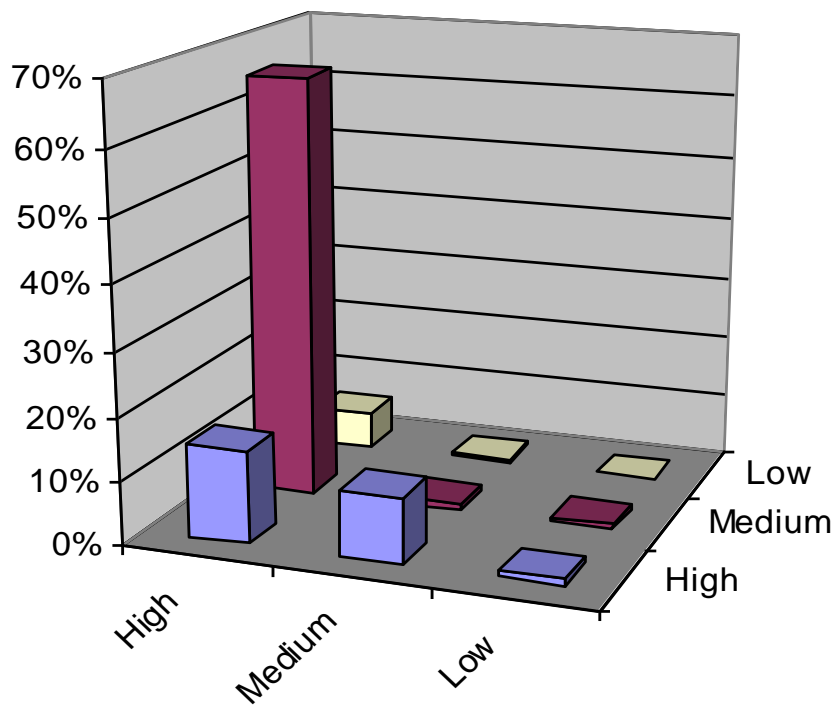

Technology Achievement of Host

\section{Technology Achievement of Investor}

What accounts for these differences? Three explanations are possible.

First, the differences could reflect not different motivations for FDI, but different distributions of host economies. Asia of course includes China, a huge mediumtechnology economy, and this alone could account for large flows to mid-technology hosts. But closer analysis suggests that this is not the whole story. High-technology Asian economies receive $27 \%$ of the region's inward FDI, considerably less than their GDP share). But these same high-technology hosts receive an even smaller share of inward FDI from Asia's own high-technology investors (16\%). In contrast to FDI patterns elsewhere, medium-technology destinations receive $66 \%$ of total inward FDI, and an even higher $78 \%$ of inward FDI from Asia's high-technology investors.

Evidently, observed patterns are not due solely to the distribution of hosts, but rather to the fact that Asian high-technology investors tend to over-invest in mid-technology hosts 
relative to high-technology hosts. Mid-technology source countries also tend to overinvest "downstream," i.e. in low-technology hosts rather than mid-technology hosts.

Second, the observed patterns could reflect differences between Asian economies and other economies that matter in determining FDI. Table 2 shows rankings for Asian and other countries for technology achievement and technology policy. (A lower rank value reflects better performance.) Asia's average rank is 43, the same as the global average rank for technology achievement, but Asia is somewhat ahead of the world average for technology policy (36 vs. 42). But regressions reported later show that a host country's technology policy is not a significant determinant of FDI in the global sample, so this factor cannot by itself explain the intensity of Asian FDI flows from advanced to less advanced economies.

TABLE 2. TECHNOLOGY ACHIEVEMENT IN ASIA

\begin{tabular}{lrrr}
\hline & GDP/capita & \multicolumn{2}{c}{ Rank of Technology } \\
& PPP 2007 & Achiev't & Policy \\
\hline Asia & 15,105 & 43 & 36 \\
China & 8,855 & 42 & 33 \\
Japan & 33,010 & 5 & 11 \\
India & 3,795 & 67 & 51 \\
NIEs & 30,627 & 13 & 14 \\
ASEAN5 & 11,747 & 55 & 57 \\
CLMV countries & 2,598 & 77 & 47 \\
Other developed & 34,796 & 12 & 14 \\
Other developing & 9,776 & 53 & 54 \\
World & 59,678 & 43 & 42 \\
\hline USD or rank (among 87 countries). & &
\end{tabular}

Finally, Asia's unusual FDI distribution could reflect differences in how FDI in Asia is determined, as compared to how it is determined in other parts of the world. Multivariate analysis will show, in fact, that is the most plausible explanation. Variables related to the technology transfer motivation play a more important role in Asia than elsewhere. For example, although host technology policy is not significant in a global setting, it is significant to Asian investors. Indeed, Asia's policies may have evolved to raise 
protection above corresponding technology achievement ranks in order to attract additional investment.

\section{Exceptional drivers of Asian FDI}

We now turn to analyzing Asian exceptionalism in the context of a gravity specification of bilateral FDI flows. Past studies consistently suggest that the principal determinants of FDI in such a framework are the size of the source and host economies and per-capita income levels, both on their own account and because they are correlated with other potentially important variables such as factor endowments. In addition, as in other applications of the model, bilateral FDI flows are expected to be related negatively to transport and communication barriers, including distance, language differences and so on.

We begin with a basic model of bilateral FDI as outlined in Equations (1-3). We then add science and technology-related variables. We next test the model's robustness to determine whether Asia is different, in two steps. First, dummy variables are introduced for FDI flows within Asia and within other regional economic groupings. This variable turns out to be significantly different from zero for Asia. Second, we show that the differences can be associated specifically with the operation of technological determinants.

The results are summarized in Table 3, which reports the four different regression that implement this approach. The estimation method used across all four cases is the censored Tobit regression model. The estimation could be potentially subject to simultaneous equations bias, since FDI could affect independent variables such as GDP/capita, and even policy variables such as science and technology policy. This problem is avoided by using independent variables at the beginning of the period for which FDI is measured. (The strategy could not be applied to the science and technology rankings, which are only available for recent years; but the simultaneous impact of FDI on technology policy is unlikely to operate quickly enough to introduce a significant bias from reverse causation.) 
The Tobit model estimates latent values for all observations, but assumes that these are realized only above a censoring limit. This amounts to assuming that the worst negative action investors can take on a bilateral link is to avoid investing. (In practice, a few data points are negative, reflecting the financial liquidation of FDI positions.) The dependent variable is censored below ln FDI=-1, or approximately $\$ 0.5$ million FDI over a five year period. Alternative lower limits do not substantially change the estimates. Many bilateral FDI flows are zero and altogether 3/4 are below the censoring limit.

Basic gravity specification. Equation 1 establishes the gravity model as a baseline for subsequent analysis. The model is consistent with expectations; all explanatory variables have expected signs and are significant at the 1 percent level. To be sure, the error of the equation is high compared to gravity models of international trade-investment behavior is more subject to idiosyncratic errors than trade.

Specifically, the distance variable is negative and highly significant. Other variables that confirm the contribution of lower barriers to FDI flows include sharing a language, and efficient air and water connections. But some other indicators that are often significant in trade equations - geographic contiguity, good highway and railway links - do not provide explanatory power for FDI and are omitted in the rest of this analysis. These variables appear to be more associated with the ease of transporting goods than with bilateral links important to investors. The host's economic size, whether due to growth population or in income per capita, has a coefficient near unity, indicating that a one-percent increase in size is associated with a similar increase in FDI inflows. But the investor's size has greater effect - both investor's population and income have coefficients larger than one. In a multivariate context, then, explanations of FDI that focus on attracting investment into large economies (such as China) appear less important than other variables. 
Table 3. Determinants of bilateral FDI flows: alternative specifications

\begin{tabular}{|c|c|c|c|c|c|c|c|c|c|c|}
\hline & \multicolumn{3}{|c|}{ Equation 1} & Equation 2 & \multicolumn{3}{|c|}{ Equation 3} & \multicolumn{3}{|c|}{ Equation 4} \\
\hline Dependent variable & \multirow{2}{*}{\multicolumn{3}{|c|}{ In FDI }} & \multirow[t]{2}{*}{ In FDI } & \multirow{2}{*}{\multicolumn{3}{|c|}{ In FDI }} & \multirow{2}{*}{\multicolumn{3}{|c|}{ In FDI }} \\
\hline Statistics & & & & & & & & & & \\
\hline Number of observations & 4830 & & & 4692 & 4692 & & & 4692 & & \\
\hline Number censored & 3636 & & & 3517 & 3517 & & & 3517 & & \\
\hline Number uncensored & 1194 & & & 1175 & 1175 & & & 1175 & & \\
\hline Chi-squared & 2226 & & & 2199 & 2282 & & & 2302 & & \\
\hline Chi-squared prob value & 0.000 & & & 0.000 & 0.000 & & & 0.000 & & \\
\hline R-squared & 0.190 & & & 0.192 & 0.199 & & & 0.200 & & \\
\hline \multicolumn{11}{|l|}{ Basic gravity specification } \\
\hline Constant & -34.64 & $(-18.3)$ & ** & $-19.70(-5.7) * *$ & -24.20 & $(-6.9)$ & ** & -26.26 & $(-7.4)$ & ** \\
\hline In distance & -2.52 & $(-19.4)$ & ** & $-2.48(-18.9)$ ** & -2.22 & $(-14.7)$ & ** & -2.15 & $(-14.3)$ & $* *$ \\
\hline In host population & 0.92 & $(13.0)$ & ** & $0.88(11.9)^{* *}$ & 0.85 & $(11.5)$ & ** & 0.86 & $(11.7)$ & ** \\
\hline In source population & 1.96 & $(24.7)$ & ** & $1.89(22.8)^{* *}$ & 1.83 & $(22.2)$ & ** & 1.84 & ( 22.3 ) & ** \\
\hline In host gdp/capita & 0.87 & $(7.7)$ & ** & $0.65(3.5)$ ** & 0.78 & $(4.2)$ & ** & 0.90 & ( 4.8$)$ & ** \\
\hline In source gdp/capita & 4.00 & $(27.0)$ & ** & $3.07(13.8)^{* *}$ & 3.30 & $(14.5)$ & ** & 3.36 & $14.6)$ & ** \\
\hline Same language & 2.70 & $(7.7)$ & ** & $2.88(8.2)$ ** & 3.19 & $(9.1)$ & ** & 3.28 & 9.3 ) & ** \\
\hline Airports & 0.99 & $2.9)$ & ** & 0.74 & 0.73 & $2.1)$ & * & 0.71 & $2.0)$ & * \\
\hline Waterways & 0.05 & $6.0)$ & ** & $5.9)^{* *}$ & 0.05 & $5.3)$ & ** & 0.05 & $5.2)$ & ** \\
\hline \multicolumn{11}{|l|}{ Science and technology } \\
\hline In host STA & & & & $-0.50(-2.6)^{* *}$ & -0.70 & $-3.6)$ & ** & -0.81 & $-4.1)$ & ** \\
\hline In host Policy & & & & $0.22(1.2)$ & 0.39 & $2.2)$ & * & 0.58 & $3.1)$ & ** \\
\hline In source STA & & & & $-0.48(-2.6)^{* *}$ & -0.60 & $-3.3)$ & ** & -0.63 & $-3.5)$ & ** \\
\hline In source Policy & & & & $-0.62(-3.7)^{* *}$ & -0.46 & $-2.8)$ & ** & -0.39 & $-2.3)$ & * \\
\hline \multicolumn{11}{|l|}{ Regional blocs } \\
\hline European Union & & & & & -0.95 & $-1.7)$ & & -0.99 & $-1.8)$ & \\
\hline MERCOSUR & & & & & 4.42 & $2.0)$ & * & 4.42 & $2.0)$ & * \\
\hline NAFTA & & & & & 0.87 & $0.4)$ & & 0.85 & $0.4)$ & \\
\hline IA (Integrating Asia) & & & & & 3.96 & $8.3)$ & ** & 2.14 & $0.9)$ & \\
\hline \multicolumn{11}{|l|}{ Asian exceptionalism } \\
\hline In host STA * IA & & & & & & & & 2.97 & 4.2 ) & ** \\
\hline In host Policy * IA & & & & & & & & -2.55 & $-3.7)$ & ** \\
\hline In source STA * IA & & & & & & & & 1.04 & $1.5)$ & \\
\hline In source Policy * IA & & & & & & & & -1.09 & $-1.5)$ & \\
\hline
\end{tabular}

** Significant at $1 \%$ level.

* Significant at 5\% level. 
Technology achievement and policy. Equation 2 extends the gravity model with technology variables. Although correlated with GDP/capita, these variables add explanatory power. With the technology variables introduced, GDP/capita variables become smaller (although significant) as they now measure more narrowly incomerelated effects, rather than higher technology associated with higher income.

Among technology variables, the largest and most significant coefficient is estimated for source country technology achievement, which presumably reflects the scale of the technological assets that drive source country FDI. (Since the independent variable is a rank, a negative coefficient means that greater achievement, or a rank closer to 1 , generates higher FDI.) The effect of the host country technology achievement is also positive; the host country's capacity for establishing high-tech branches is especially important in horizontal FDI strategies. The coefficients for technology policy are more ambiguous: the coefficient is significant for the source country, possibly due to the fact that better local policies generate greater technological assets. The coefficient is positive and insignificant in the host country. A positive coefficient is unexpected, but it could reflect the fact that a strong environment for technology makes licensing relatively attractive compared to FDI.

Regional differences. With the fully specified model, we next explore the possibility of regional differences. A first pass is reflected in Equation 3, which incorporates dummy variables for bilateral flows that are within one of the world's major regional blocs: the European Union, MERCOSUR, NAFTA and "Integrating Asia." The connections within such blocs - which reflect official agreements as well as intensified market contactscould be expected to diminish barriers to FDI flows as well.

The "Integrating Asia" bloc differs from the others as it has not yet adopted region-wide trade and investment agreements. This group is defined to include 16 economiesChina, Japan, India, the East Asia NIEs, and ASEAN — that have already made significant progress in regional integration, so far principally through market forces 
(ADB 2008). Within this region, only ASEAN has a comprehensive integration agreement. ASEAN has also made strides in recent years in expanding its "hub" through bilateral partnership agreements with China, Korea, Japan, India and Australia and New Zealand. The ASEAN hub represents the core of a new bloc, but the agreements are new and relatively weak, and formal links among the region's economic giants (China, Japan and Korea) remain elusive. For all these reasons, one might expect the implications of membership in "Integrating Asia" to be less significant than membership in the other, more formal regional groupings.

In fact the opposite is the case. Flows within Integrating Asia are the most significantly different from FDI flows in other regions. They are as much above normal flows as flows in MERCOSUR, which is typically considered the most inward-looking of the regional blocs. Flows within the EU are slightly lower than other bilateral flowspresumably the high level of such flows is adequately explained by the positive effects of the general determinants of FDI within Europe, such as close geographical proximity and low barriers to communications, high income, and high technology achievement in both source and host countries.

Differential effects of science and technology in Asia. As noted, the distinguishing characteristic of intra-Asian FDI flows is that they connect high-tech with medium-tech economies. Equation 4 explores whether this phenomenon can be traced to the different effects of the science and technology variables in the intra-Asian context. Equation 4 therefore adds a set of interaction terms between the technology variables and the IA variable, in effect identifying an Asian increment to the coefficients of those variables in the context of other global FDI flows.

Two coefficients significant in the global regression-source country technology achievement and policy_are not significantly different for Asia. This suggests that Asian technological assets, which depend on achievement and policy, play a similar role in generating FDI in Asia in other regions. But the remaining two technology coefficients, both reflecting host country characteristics, show significant Asian 
differences. Intra-Asian flows are higher if the host has lower science and technology achievement (its rank is a relatively high number), and if the host has stronger technology policies (its rank is a relatively low number). In effect, the "Asian increment" reverses the signs of both coefficients from the general equation. Intra-Asian FDI is evidently focused on the transfer of technology from high to low-achievement countries, and is especially intense when the host's technology policies are favorable. The intra-Asian technology interactions terms also make the coefficient of the Integrating Asia dummy insignificant. In other words, the differential effect of science and technology variables in Asia appears to fully explain how Asia is different, and the general Asian dummy variable adds no further explanatory power.

\section{Conclusions}

Although Asia's early developers obtained technology from foreign sources through a variety of means, including both legal and illegal imitation, recent developers have actively promoted the acquisition of technology through FDI inflows. This study has tried to assess to what extent technological differences have motivated such flows, and what impact technology policies may have had on them. In both of these respects, Asian FDI turns out to differ significantly from those in other parts of the world.

Unlike FDI flows in other regions, Asian flows tend to connect high-tech economies with those at lower rungs of the technology ladder. The technology achievement gap between the investor and the host appears as a significant positive factor in Asian FDI, while it appears as a negative factor in the bilateral FDI links of other countries. In addition, in Asia, the technology policy of the host country turns out to be significant driver for inward FDI, while it's insignificant (and negatively signed) determinant of FDI among other countries. This is consistent with the view that Asian investments carry substantial know-how from the investing countries to hosts, and that the investor is concerned with ensuring that its intellectual property is protected abroad.

The finding that FDI has strong technological drivers and is sensitive to the technology policies of host countries provides additional motivation for FDI-friendly development 
strategies, such as those practiced by Asia's recent developers. While this study has not examined the spillovers that result from such inflows, in combination with evidence of such spillovers from other studies, the findings provide a rationale for active FDI policy.

Overall, the study supports the "flying geese" view of Asian development. Except for the region's early developers, the acquisition of technology has been facilitated by the unusual willingness of Asian firms to invest in technologically less advanced areas, presumably to stretch out the life of their technology assets while taking advantage of more favorable production conditions abroad. The region's NIEs have been especially active participants in these flows. Anecdotal evidence from other work suggests that often small firms are involved. This powerful conduit for passing know-how from more advanced to less advanced economies has enabled economies to move up the technology ladder, graduating to more advanced production processes and eventually a role in their own technology exports. 


\section{REFERENCES}

Akamatsu, K. (1962) "A historical pattern of economic growth in developing countries." The Developing Economies, Vol. 1, pp. 3-25.

Blonigen, Bruce A. (2005) "A Review of the Empirical Literature on FDI Determinants" NBER Working Paper.

Brainard S. L. (1993) "A Simple Theory of Multinational Corporations and Trade with a Trade-off between Proximity and Concentration” NBER Working Paper N. 4269, February.

Brainard S.L. (1997) “An Empirical Assessment of the proximity-concentration Tradeoff between Multinational Sales and Trade" American Economic Review Vol. 87, N. 4.

Brenton, P. and Di Mauro, F. (1999) "The Potential Magnitude and Impact of FDI flows to CEECs", Journal of Economic Integration, Vol. 14 N. 1, March, pp. 59-74.

Carr D., Markusen J. R. and Maskus K. (2001) "Estimating the Knowledge-Capital model of the multinational enterprise" The American Economic Review, Vol. 91, No. 3 (June), pp. 693-708.

Damijan, J. P. and Matija Rojec (2007) "Foreign Direct Investment and Catching Up of New EU Member States: Is There a Flying Geese Pattern?" Applied Economics Quarterly, 53:2, pp. 91-118.

Du, Luosha, Ann Harrison and Gary Jefferson, (2010). "Are FDI Spillovers Horizontal or Vertical? Firm-Level Evidence from China." Journal of Asian Economics, this issue.

Dunning J. (1977) "Trade, Location of Economic Activity and MNE: A Search for an Eclectic Approach" in Ohlin B., Hesselborn P. And Wijkman P/M/ eds. The International Allocation of Economic Activity, Macmillan, London.

Eaton, J. and A.Tamura (1994), "Bilateralism and Regionalism in Japonese and U.S. Trade and Direct Foreign Investement Patterns", Journal of the Japanese and International Economies 8 :478-510.

Globerman, S. and D. Shapiro (2002), "Global Foreign Direct Investment Flows: The Role of Governance Infrastructure”, World Development 30(11) :1899-1919.

Habib, M., and L. Zurawicki (2002), "Corruption and Foreign Direct Investment", Journal of International Business Studies 33 (2).

Helpman E. (1984) “A Simple Theory of International Trade with Multinational 
Corporations" Journal of Political Economy, Vol. 92, N. 31.

Horst, Alexandra C. (2007). International Property Rights Index, 2007 Report, Washington: Property Rights Alliance.

International Finance Corporation (2008). Doing Business. Washington: IFC/World Bank.

Kojima, Kiyoshi, (2000). "The flying geese model of Asian economic development: origin, theoretical extensions, and regional policy implications." Journal of Asian Economics, Vol. 11, pp. 375-401.

Kinoshita, Y., and N. Campos (2003), "Why Does FDI Go Where it Goes? New Evidence from the Transition Economies", Williamson Institute Working paper, 573.

Lucas R. (1990), “Why Doesn't capital Flow from Rich to Poor Countries ?", American Economic Review 80 (2) 92-96.

Magee, Christopher S. (2003). "Endogenous Preferential Trade Agreements: An Empirical Analysis," The B.E. Journal of Economic Analysis \& Policy: Vol. 2: Iss. 1 (Contributions), Article 15. Available at:

http://www.bepress.com/bejeap/contributions/vol2/iss1/art15

Markusen, James R. (1995). "The Boundaries of Multinational Enterprises and the Theory of International Trade" The Journal of Economic Perspectives, Vol. 9, No. 2. (Spring) pp. 169-189.

Markusen J.R and Maskus K. (1999). "Multinational firms: Reconciling Theory and Evidence" NBER Working Paper N. 7163, June.

Markusen J.R. and Venables A.J. (1998). "Multinational Firms and the New Trade Theory" Journal of International Economics Vol. 46, 183-203.

Motta M. and Norman G. (1996) "Does economic integration cause foreign direct investment?" International Economic Review Vol. 37, N. 4, November.

Petri, Peter A. (1988). "Korea's Export Niche: Origins and Prospects," World Development, Vol. 16(1), pp. 47-63.

Saggi, Kamal (2002). "Trade, Foreign Direct Investment, and International Technology Transfer: A Survey." The World Bank Research Observer, Vol. 17, No. 2 (Autumn), pp. 191-235.

UNCTAD (various issues) World Investment Report, Geneva.

Wheeler, D., and A. Mody, (1992). "International investment location decisions. The 
case of U.S. firms", Journal of International Economics, 33 : 57-76.

$\mathrm{Xu}$, Xinpeng and Yu Sheng, (2010). “Are FDI Spillovers Regional? Firm-Level Evidence from China." Journal of Asian Economics, this issue. 
ANNEX

VARIABLE DEFINITIONS

\begin{tabular}{|c|c|c|}
\hline Variable & Definition & $\begin{array}{l}\text { Source } \\
\end{array}$ \\
\hline Distance & $\begin{array}{l}\text { Distance between capitals, } \\
1000 \mathrm{~km}\end{array}$ & Magee (2003) \\
\hline Same language & $\begin{array}{l}=1 \text { if countries have the } \\
\text { same official language }\end{array}$ & Magee (2003) \\
\hline Waterways & $\begin{array}{l}\text { Km of waterways per } 1000 \\
\text { sq km }\end{array}$ & Magee (2003) \\
\hline Airports & $\begin{array}{l}\text { Paved airports per } 1000 \mathrm{sq} \\
\mathrm{km}\end{array}$ & Magee (2003) \\
\hline European Union & $\begin{array}{l}=1 \text { if bilateral trade within } \\
\text { EU25 }\end{array}$ & Magee (2003) \\
\hline MERCOSUR & $\begin{array}{l}=1 \text { if bilateral trade within } \\
\text { MERCOSUR }\end{array}$ & Magee (2003) \\
\hline NAFTA & $\begin{array}{l}=1 \text { if bilateral trade within } \\
\text { NAFTA }\end{array}$ & Magee (2003) \\
\hline IA (Integrating Asia) & $\begin{array}{l}=1 \text { if ASEAN, China, } \\
\text { India, Korea, Hong Kong, } \\
\text { Taiwan }\end{array}$ & Constructed \\
\hline Population & Millions & $\begin{array}{l}\text { World Development } \\
\text { Indicators (2008) }\end{array}$ \\
\hline GDP/Capita & USD 2000 & $\begin{array}{l}\text { World Development } \\
\text { Indicators (2008) }\end{array}$ \\
\hline GDP & USD billions 2000 & $\begin{array}{l}\text { World Development } \\
\text { Indicators (2008) }\end{array}$ \\
\hline FDI & USD millions & UNCTAD special dataset \\
\hline $\begin{array}{l}\text { Science and technology } \\
\text { achievement index }\end{array}$ & $\begin{array}{l}\text { Composite rank of } 87 \\
\text { countries }\end{array}$ & $\begin{array}{l}\text { UN Human Development } \\
\text { Report (2008) }\end{array}$ \\
\hline $\begin{array}{l}\text { Science and technology } \\
\text { policy index }\end{array}$ & $\begin{array}{l}\text { Composite rank of } 87 \\
\text { countries }\end{array}$ & $\begin{array}{l}\text { IFC Doing Business and } \\
\text { Horst (2007) }\end{array}$ \\
\hline
\end{tabular}

